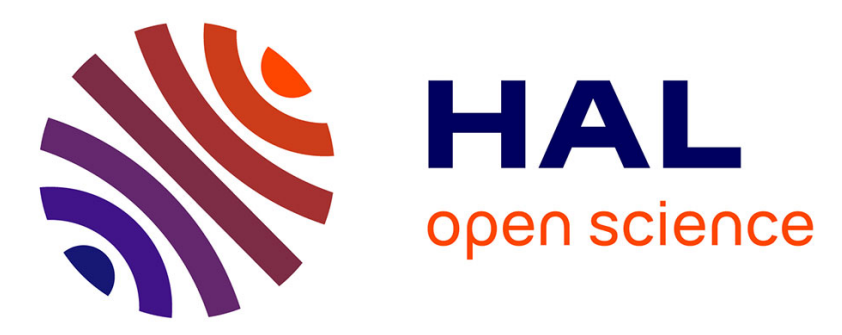

\title{
Improved measurement methods for autogenous shrinkage of cement mortars at very early age
}

Marwen Bouasker, Frédéric Grondin, Pierre Mounanga, Arnaud Pertué, Abdelhafid Khelidj

\section{- To cite this version:}

Marwen Bouasker, Frédéric Grondin, Pierre Mounanga, Arnaud Pertué, Abdelhafid Khelidj. Improved measurement methods for autogenous shrinkage of cement mortars at very early age. International conference Advances in Concrete through Science and Engineering, Sep 2006, Québec, Canada. hal01008297

\section{HAL Id: hal-01008297 \\ https://hal.science/hal-01008297}

Submitted on 8 Jun 2018

HAL is a multi-disciplinary open access archive for the deposit and dissemination of scientific research documents, whether they are published or not. The documents may come from teaching and research institutions in France or abroad, or from public or private research centers.
L'archive ouverte pluridisciplinaire HAL, est destinée au dépôt et à la diffusion de documents scientifiques de niveau recherche, publiés ou non, émanant des établissements d'enseignement et de recherche français ou étrangers, des laboratoires publics ou privés. 


\title{
IMPROVED MEASUREMENT METHODS FOR AUTOGENOUS SHRINKAGE OF CEMENT MORTARS AT VERY EARLY AGE
}

\author{
Marwen Bouasker, Frédéric Grondin, Pierre Mounanga, Arnaud Pertué and \\ Abdelhafid Khelidj
}

GeM UMR CNRS 6183 - Research Institute in Civil Engineering and Mechanics

IUT Saint-Nazaire, 58 rue Michel Ange, BP 420, F-44606 Saint-Nazaire, France

\begin{abstract}
This paper presents improved test methods for the measurement of autogenous shrinkage of cement-based materials at very early age ( 0 to $48 \mathrm{~h})$. These five test methods enable the measurement of chemical shrinkage, volumetric autogenous shrinkage, linear autogenous shrinkage in horizontal and vertical directions and restrained autogenous deformations leading to early-age cracking of the material. The first experimental results are discussed and analyzed. It was shown that the presence of granular inclusions slightly accelerates the evolution of mortar chemical shrinkage. The rotary test device for the measurement of volumetric autogenous shrinkage makes it possible to eliminate bleeding and segregation problems related to medium or high water-to-cement ratio (W/C). The use of non-contact and waterproof eddy current sensors permits to quantify uniaxial autogenous deformations of the cementitious matrices since the casting of the material, in quasi-isothermal conditions. Finally, it is shown from ring test results that the age of cracking decreases when the temperature increases, but the cracking appears at nearly the same hydration degree.
\end{abstract}

\section{1.}

INTRODUCTION

Autogenous shrinkage is known as one of the phenomena involved in premature (micro) cracking of cement-based materials used in Civil Engineering buildings and constructions. In restrained conditions, early age shrinkage can lead to the formation of both micro-cracks, in the surrounding environment of the aggregates, and crossing cracks, in the cementitious matrix. It results in an increase of the material porosity and consequently in a loss of the containment characteristics and an augmentation of the permeability. The durability of concrete buildings depends then, on the dimensional variations of the cementitious matrices at very early age.

Autogenous shrinkage is a physico-chemical phenomenon coupled with mechanical capillary effects due to pore water consumption by the hydration reactions. At 24 hours of 
hydration, it can represent more than $40 \%$ of the autogenous shrinkage value measured after one year of hydration [1].

During the first stages of hydration (since the first contact between water and cement until the setting), the capillary effects can be considered as negligible and autogenous shrinkage is mainly considered as chemical one (also called «Le Chatelier's contraction») [2]. Then, the development of the solid mineral skeleton slows down the deformations of the material and the autogenous shrinkage curve starts to diverge from the Le Chatelier's contraction curve. The self-desiccation of the cementitious matrix becomes the driving mechanism of the autogenous shrinkage. The mechanical resistance of the material gradually increases with the progress of the hydration reactions and the interaction between cement paste and aggregates comes into place.

Measurement of cement-based material deformations at very early age is a major problem [3]. Indeed, standard methods for shrinkage measurement are suitable to hardened cementitious systems but cannot be applied during the very early age of the material and particularly during the fluid - solid transition (setting period). It is therefore necessary to propose improved experimental methods adapted to the complex behaviour of fresh cementbased matrices.

The present research work forms part of an extensive study on the influence of matrixinclusion interactions on autogenous shrinkage of mortars. Firstly, five measurement methods especially adapted for the study of the early age deformation of cementitious matrices are described. These methods are then used to measure the volumetric and linear variations of hydrating cement pastes and mortars. The effects of granular inclusions type, water-to-cement ratio $(\mathrm{W} / \mathrm{C})$ and curing temperature are analyzed and discussed.

\section{EXPERIMENTAL PROGRAM}

Five different measurement methods have been developed for the study of the early age volume changes of cement-based materials: these experimental methods permit to measure continuously and automatically, from the end of casting to 48 hours, the chemical shrinkage, the volumetric autogenous shrinkage, the linear autogenous shrinkage in both horizontal and vertical directions and the restrained autogenous deformations leading to the premature cracking of the material.

These methods are applied to cement pastes with different $\mathrm{W} / \mathrm{C}$ ratios $(\mathrm{W} / \mathrm{C}=0.25 ; 0.30$ and 0.40 ) and mortars prepared with various types of granular inclusions (glass balls and natural sand). The cement used is a Type I ordinary Portland cement (CEM1).

During the tests, precautions are taken to maintain quasi-isothermal conditions in order to decouple pure physico-chemical deformations from thermal deformations caused by the hydration heat release. The experimental systems used for free volume or length change recording are placed in a thermostatic water bath during the whole period measurement (see figure 1). The ring test device used for the measurement of restrained deformations is equipped with a peripheral water circulation system acting as a thermal regulation.

The following sections describe more precisely each experimental apparatus. 


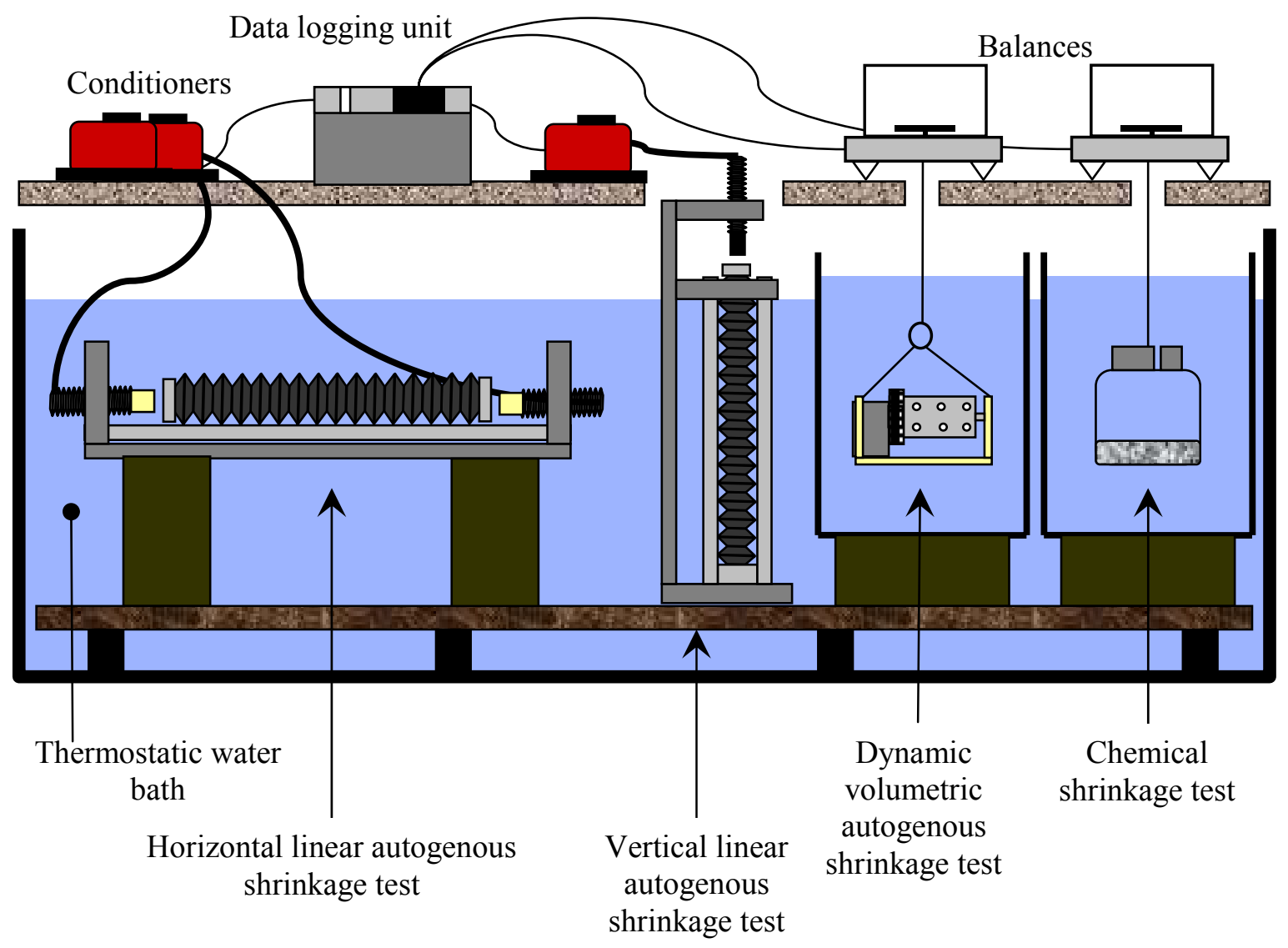

Figure 1: Schematic of the specific experimental bench for the free deformation measurements of early age cementitious systems

\subsection{Chemical shrinkage measurement}

The chemical shrinkage is measured ensuring the permanent water saturation of the hydrating material pore space. A gravimetric method is used $[4,5]$ : it consists in recording the buoyancy variation of a sample of cement paste or mortar placed in a flask with an orifice on its cap. The whole system is immersed in water and hung to a balance. The detailed description of the method and protocol can be found in [6]. The main parameters of the test method are given in table 1 .

Table 1: Test parameters for Le Chatelier's contraction measurement

\begin{tabular}{|l|l|}
\hline \multicolumn{1}{|c|}{ Test parameters } & \multicolumn{1}{c|}{ Values } \\
\hline Sample mass & $20-30 \mathrm{~g}$ \\
\hline Exchange surface area between sample and water & $20 \pm 1 \mathrm{~cm}^{2}$ \\
\hline Sample thickness & $9 \pm 1 \mathrm{~mm}$ \\
\hline Liquid of immersion & Distilled water \\
\hline Water bath temperature & $20 \pm 1^{\circ} \mathrm{C}$ \\
\hline
\end{tabular}




\subsection{Dynamic volumetric autogenous shrinkage measurement}

This method is based on the "condom method", which consists in recording the buoyancy variation of a latex membrane filled with fresh material, immersed in a liquid bath and hung to a balance. Several researchers already pointed out the experimental artefacts of this test method [7, 8]. Among them, the pressure of the membrane on the solidifying matrix, the bleeding phenomenon and the water absorption by the membrane are the most significant.

In order to limit water absorption by the latex membrane, the empty membrane is saturated during 24 hours before starting the test. The measurement system has also been improved to eliminate the effect of bleeding by putting the sample in rotation during the whole test period. The device, presented in figure 2, is composed of a PVC cylinder equipped with a toothed wheel connected to a micro-motor by the intermediary of a driving belt. The micro-motor has been waterproofed with silicon gel. Its rotation speed is controlled by a regulated power supply. The micro-motor, the PVC cylinder and the transmission system (toothed wheel and belt) are assembled on a PVC base hung, by nylon threads, to a balance linked to a computer for automatic recording of the system buoyancy variations. The measurement of volume changes starts ten minutes after the placing of the sample in the PVC cylinder. Table 2 recapitulates the principal parameters of the testing method.

Table 2: Test parameters for dynamic volumetric autogenous shrinkage measurement

\begin{tabular}{|l|l|}
\hline \multicolumn{1}{|c|}{ Test parameters } & \multicolumn{1}{c|}{ Values } \\
\hline Sample mass & $100-120 \mathrm{~g}$ \\
\hline Device mass & $570 \mathrm{~g}$ \\
\hline Micro-motor velocity & 12 rotations per minute \\
\hline Liquid of immersion & Distilled water \\
\hline Water bath temperature & $20 \pm 1^{\circ} \mathrm{C}$ \\
\hline
\end{tabular}

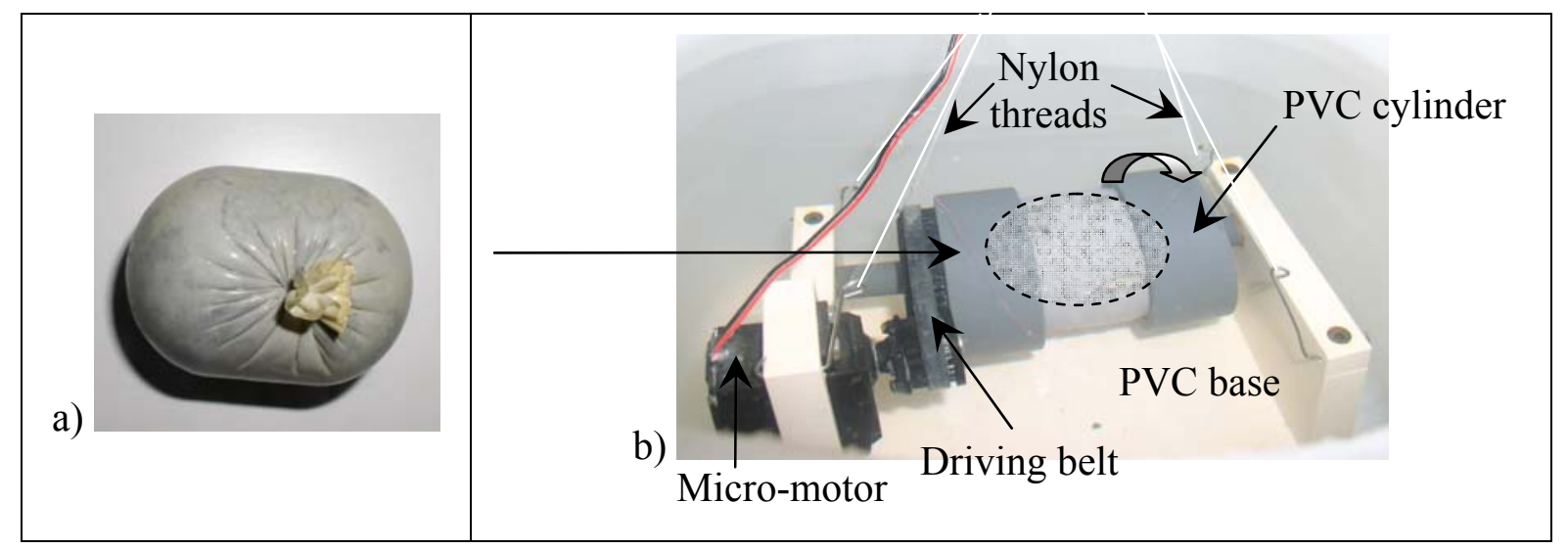

Figure 2: Dynamic volumetric autogenous shrinkage measurement device (a- Sample, b- Rotary system) 


\subsection{Horizontal and vertical linear autogenous shrinkage measurement}

The linear autogenous deformations of cementitious matrices are measured in both horizontal and vertical directions (see figure 3). The experimental system is composed of a ringed flexible moulded polyvinyl chloride (PVC) membrane filled with fresh cement paste or mortar. Precautions are taken to avoid the introduction of air bubbles during the casting of the material. The membrane is sealed with metallic caps and positioned on a rigid PVC frame.

For the "horizontal device", two sensors are placed at each end of the frame. The sensors are waterproof non-contacting displacement measuring system operating on the eddy current principle. This characteristic (waterproof sensors) is important because it makes it possible to maintain the experimental device under water and keep the sample in quasi-isothermal conditions.

For the "vertical test" device, the length changes are measured by a laser sensor located at the top of the experimental system. This sensor is not waterproof: only the lower part of the frame and the membrane filled with cement-based material are immersed in water during the test.

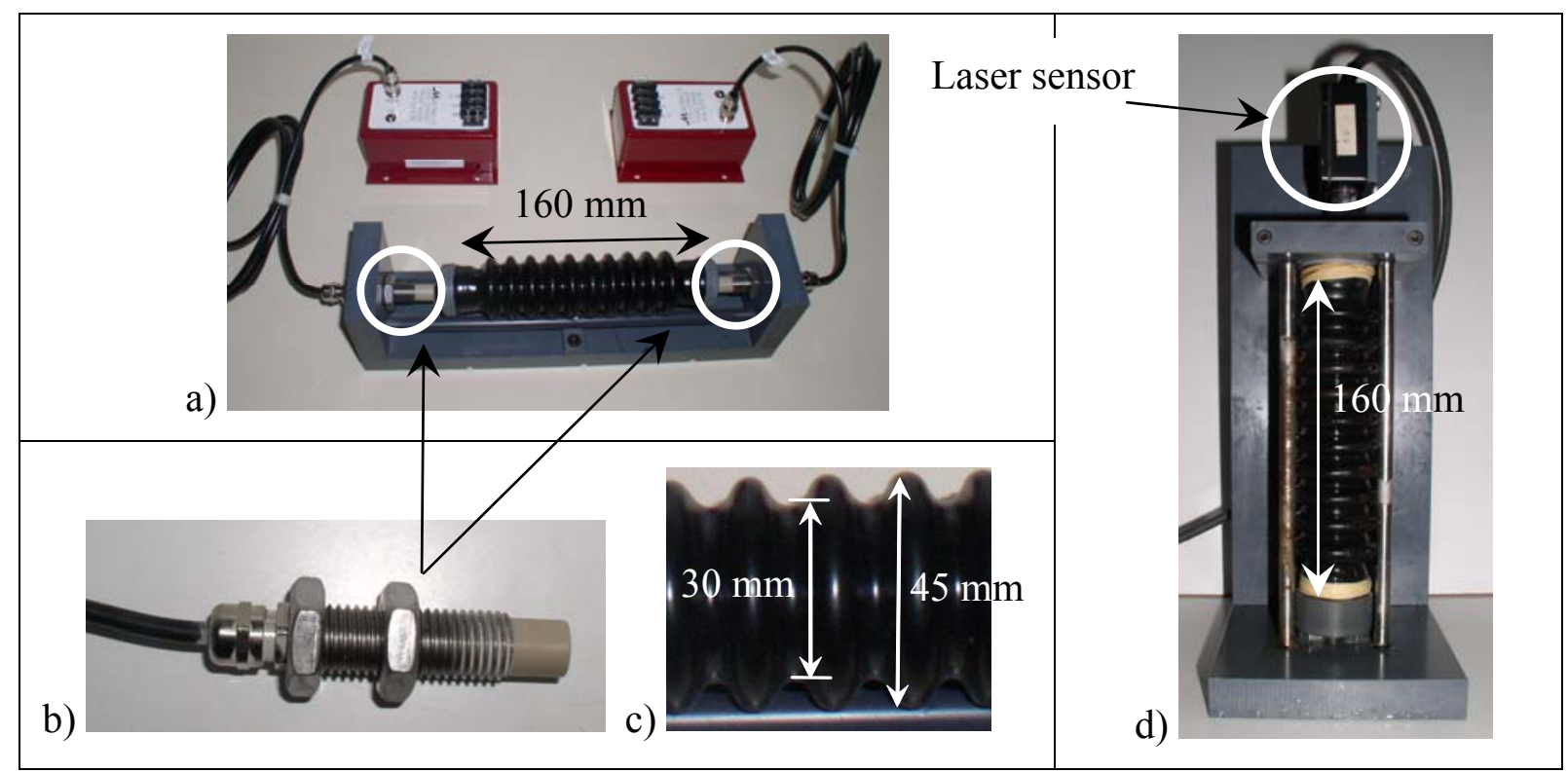

Figure 3: Linear autogenous shrinkage measurement devices (a- Horizontal system, bWaterproof eddy-current sensors, c- Flexible PVC membrane, d- Vertical system)

\subsection{Restrained deformations: quasi-isothermal ring test device}

The deformations in restrained conditions are measured using the "ring test" method [9]. The quasi-isothermal conditions during the tests are ensured by a peripheral water circulation system, whose temperature is controlled by a thermostatic water bath. Photographs and dimensions of the ring test device are given on figures 4 and 5. At the beginning of each test, the fresh cement-based material is cast around the steel ring equipped with strain gauges connected to a data acquisition system.

The device permits to follow automatically the deformations of the steel ring and to detect the moment of the cement-based material cracking. In this study, two isothermal curing temperatures $\left(\mathrm{T}=20^{\circ} \mathrm{C}\right.$ and $\left.25^{\circ} \mathrm{C}\right)$ have been imposed to the samples. 


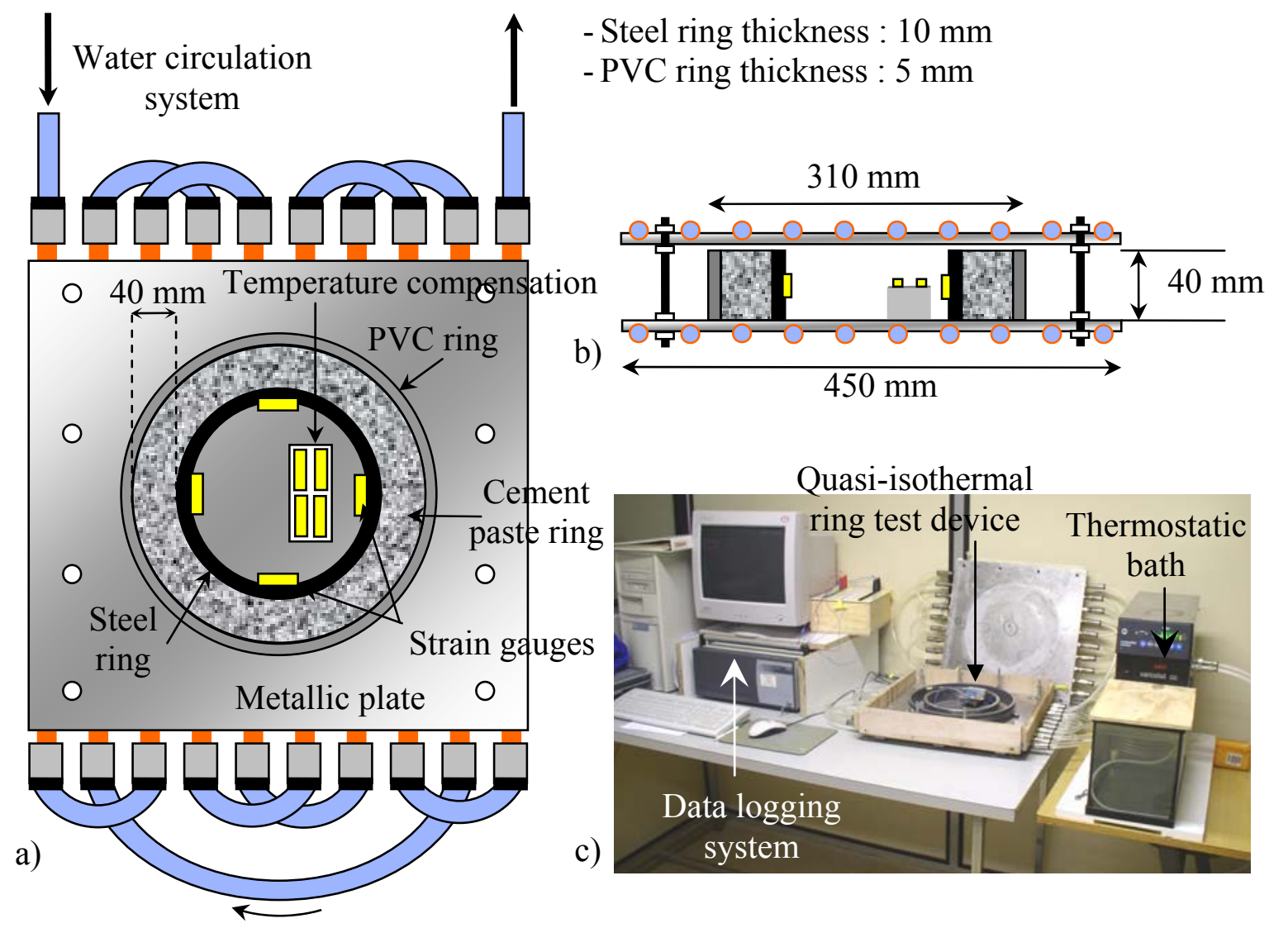

Figure 4: Diagrams (a- Top view, b- Side view) and general view (c) of the quasi-isothermal ring test device

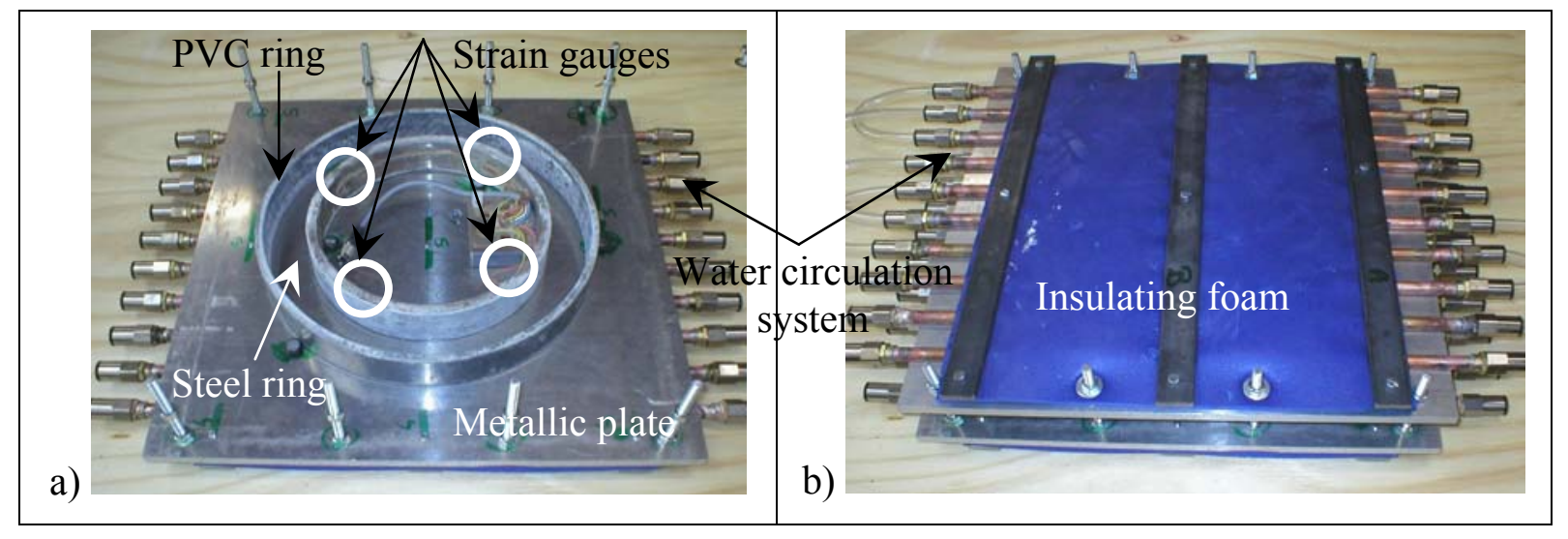

Figure 5: Quasi-isothermal ring test device (a- Dismantled system, b- Set up system) 


\subsection{Chemical shrinkage}

Figure 6 presents the evolution of the chemical shrinkage between 1 and $24 \mathrm{~h}$ of hydration of mortars prepared with different $\mathrm{W} / \mathrm{C}$ ratios $(0.30$ and 0.40$)$, aggregates of different types (natural sand and glass balls), diameters $(1 \mathrm{~mm}$ and $2 \mathrm{~mm})$ and concentrations $\mathrm{A} / \mathrm{C}(\mathrm{A} / \mathrm{C}=0.5$ and 1). The curves obtained are almost superimposed up to $8 \mathrm{~h}$ of hydration; beyond this first period, they form a tight spindle until the end of the investigation period.

A modification of $\mathrm{W} / \mathrm{C}$ ratio, granular concentration or type only causes a weak variation of the kinetics and the amplitude of the chemical shrinkage of the studied mortars. A $24 \mathrm{~h}$, the maximum difference observed, equal to $11 \%$, is located between the final curve amplitudes of the mortars with the same $\mathrm{W} / \mathrm{C}$ and $\mathrm{A} / \mathrm{C}$ prepared with aggregates of different sizes ("Sand $(1 \mathrm{~mm}) \mathrm{W} / \mathrm{C}=0.4 \mathrm{~A} / \mathrm{C}=0.5$ " and "Sand $(2 \mathrm{~mm}) \mathrm{W} / \mathrm{C}=0.4 \mathrm{~A} / \mathrm{C}=0.5$ "). This difference between the two curves can be explained by a more efficient mixing in the presence of the "1 mm" aggregates. Indeed, considering a constant granular mass fraction, the finer aggregates are more numerous and their granular specific surface per gram of sample is larger: the number of cement clusters broken by shearing or impact with sand grains is then larger and the amount of cement directly in contact with water becomes more important. It results in higher amplitude of chemical shrinkage of the mortar prepared with "1 mm" aggregates.

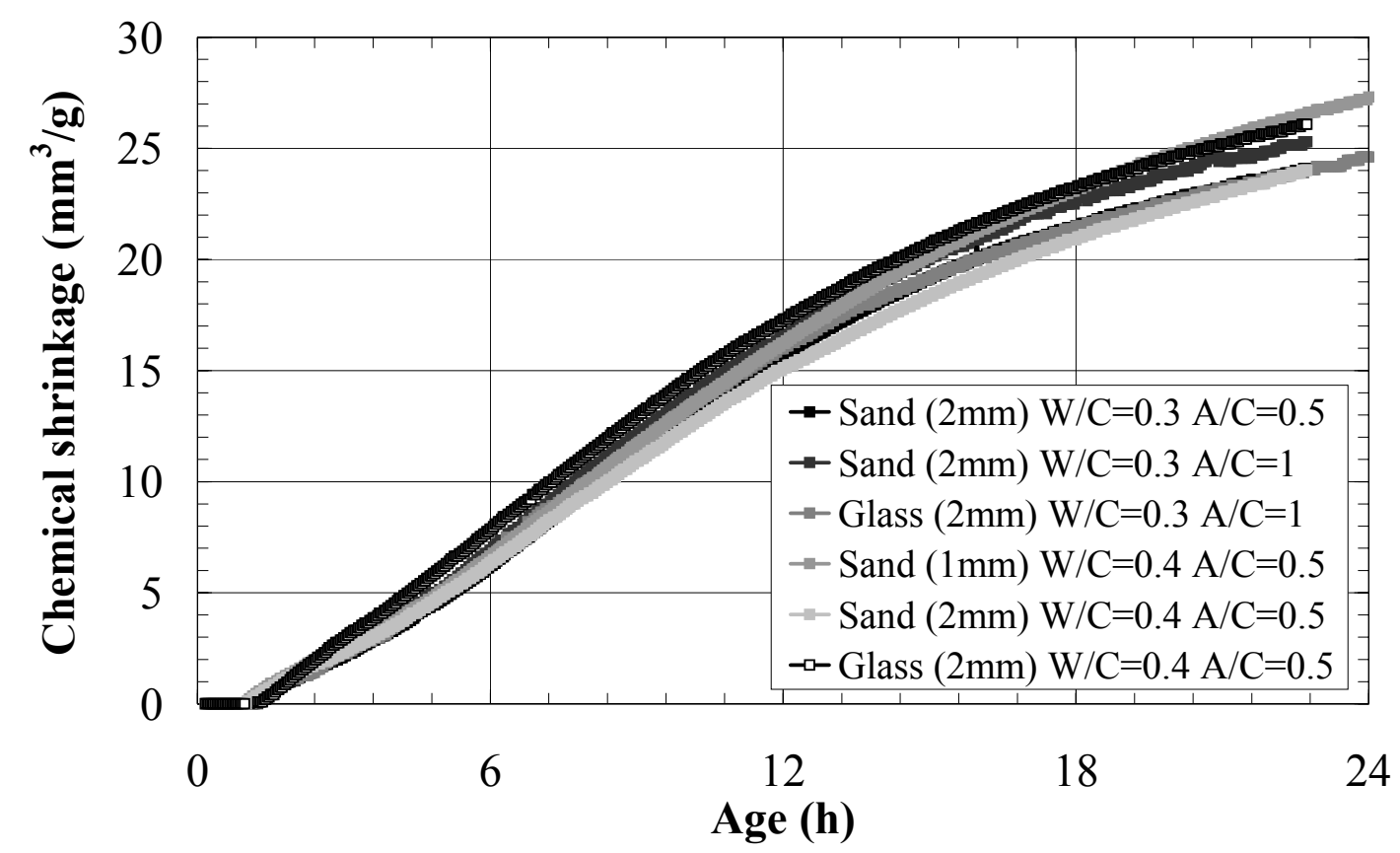

Figure 6: Chemical shrinkage vs. hydration age at $\mathrm{T}=20 \pm 1{ }^{\circ} \mathrm{C}$

Does this influence modify the quasi-linear relation between the chemical shrinkage and the hydration degree of the cementitious matrices? To elucidate this point, the evolution of the chemical shrinkage is plotted in figure 7 as a function of hydration degree measured by loss on ignition between 145 and $950^{\circ} \mathrm{C}$. It is observed that for the various studied mortars, the 
evolution of the chemical shrinkage linearly increases with the hydration progress. The slope of this linear function is appreciably the same for the whole prepared mixtures.

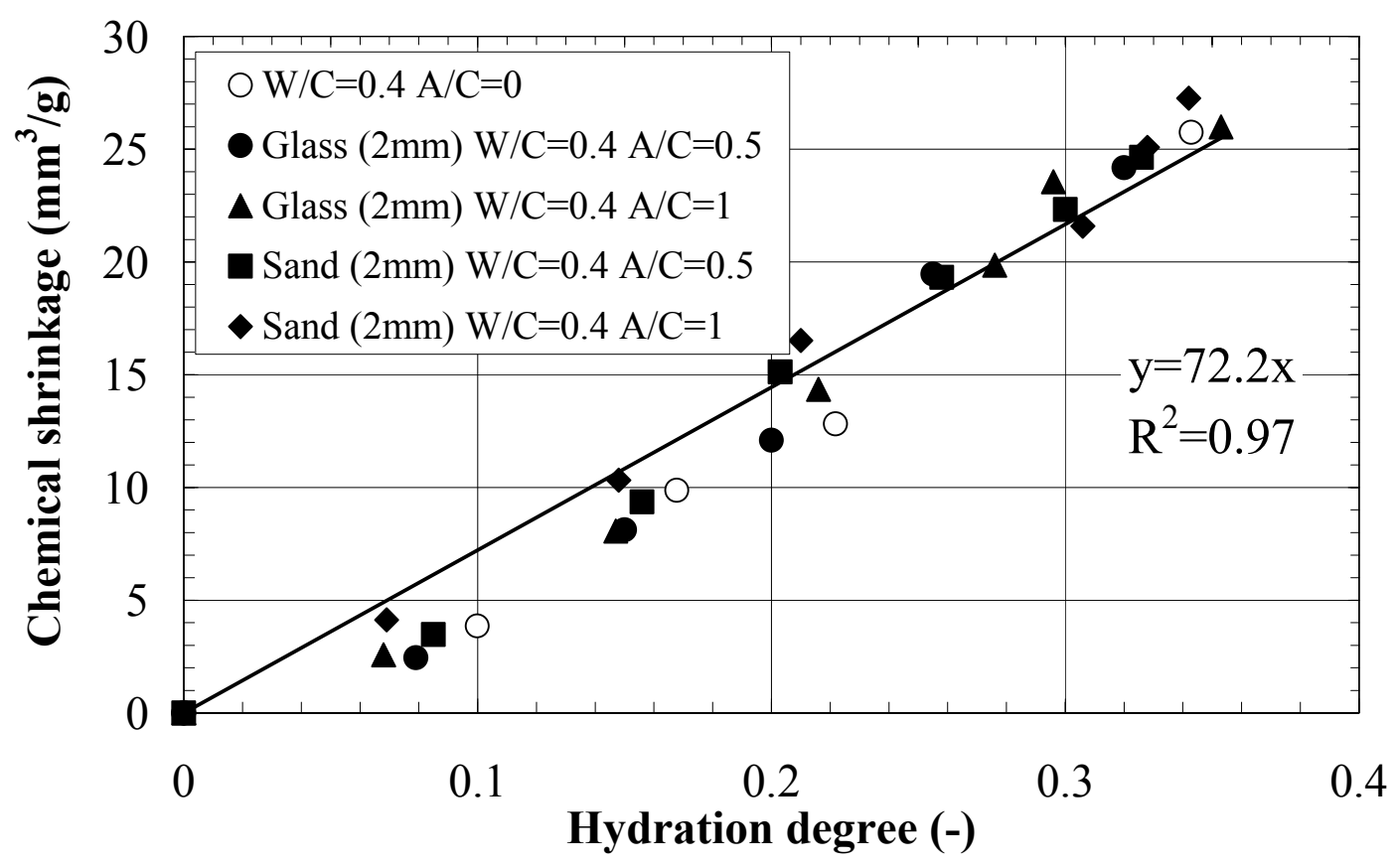

Figure 7: Chemical shrinkage vs. hydration degree at $\mathrm{T}=20 \pm 1{ }^{\circ} \mathrm{C}$

\subsection{Volumetric autogenous deformation}

It is important to remind the complexity of the measurement of cementitious matrix volume changes in particular for the matrices with high $\mathrm{W} / \mathrm{C}$ ratio because of the bleeding risk. Justnes et al. [7] already observed that this phenomenon tends to over-estimate the autogenous deformations at very early age.

In order to avoid this artefact, a rotary volume change measurement device has been developed: it enables to measure the volume variations of a latex membrane filled with cement paste or mortar and put in rotation during the whole investigation period. For the validation of the system, we applied it to two different cement pastes, the first without bleeding $(\mathrm{W} / \mathrm{C}=0.25)$ and the second presenting a strong bleeding risk $(\mathrm{W} / \mathrm{C}=0.4)$.

Figure 8 displays the results obtained with the $\mathrm{W} / \mathrm{C}=0.25$-cement paste. The curves are initialized at $1 \mathrm{~h}$ of hydration in order to eliminate the disturbances observed at the beginning of the test. These disturbances are due to the movement of the sample, which is still fluid, inside the cylinder in rotation. The comparison between the curves obtained with the rotary device and those measured by Mounanga [10] in static conditions (no rotation) shows that the both test methods give very similar results for cement pastes with low W/C ratio.

Figure 9 presents the results of volumetric autogenous shrinkage measurement of cement pastes with $\mathrm{W} / \mathrm{C}=0.40$ with and without rotation of the sample. These results are compared with the chemical shrinkage evolution of $\mathrm{W} / \mathrm{C}=0.40$-cement pastes presented by Mounanga et al. in 2004 [6]. It can be noted that in static conditions, the period of volume changes corresponding to Le Chatelier's contraction is much longer than in the case of dynamic measurement. This phenomenon is explained by the formation of a water film between the 
membrane and the sample in static conditions which artificially extends the period of Le Chatelier's contraction. During the dynamic test, this film does not have time to be formed and the bleeding effect is avoided. The initializing of the deformations at 15 hours of hydration (figure 10), i.e. beyond the knee-point marking the transition between chemical deformations and self-desiccation shrinkage, underlines that the volume changes measured in static and in dynamic conditions are completely superimposed: at this stage of hydration, the bleeding of the sample does not have any more influence on the material deformation.

As a matter of fact, for cement-based systems with high W/C ratio, measurement methods in static conditions or with continuous rotation cannot provide the real autogenous deformations observed in actual field conditions:

- In static conditions, the measured shrinkage is very over-estimated due to the extension of Le Chatelier's contraction phase induced by the bleeding phenomenon;

- In continuous rotation, bleeding is avoided and the sample remains homogeneous during the test period.

Field conditions are situated somewhere between these two test conditions.

Therefore, the function of the dynamic volumetric autogenous shrinkage device is not to reproduce completely field conditions but rather to permit the measurement of the volume change of a "perfectly" homogeneous sample, decoupling physico-chemical phenomena (chemical shrinkage, setting, self-desiccation) from bleeding and sedimentation phenomena.

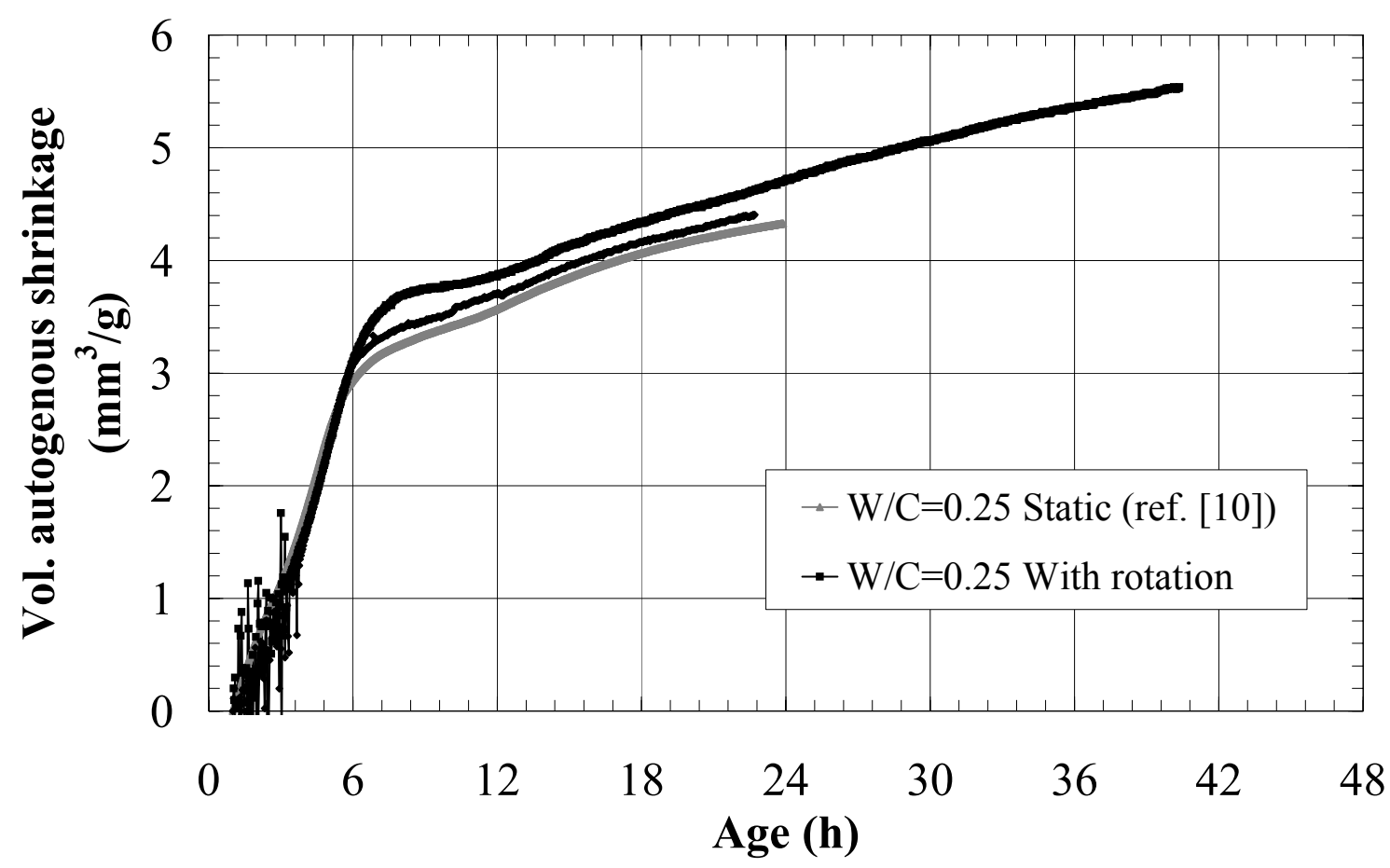

Figure 8: Volumetric autogenous shrinkage vs. hydration age

(Cement paste with $\mathrm{W} / \mathrm{C}=0.25$ at $\mathrm{T}=20 \pm 1^{\circ} \mathrm{C}$ ) 


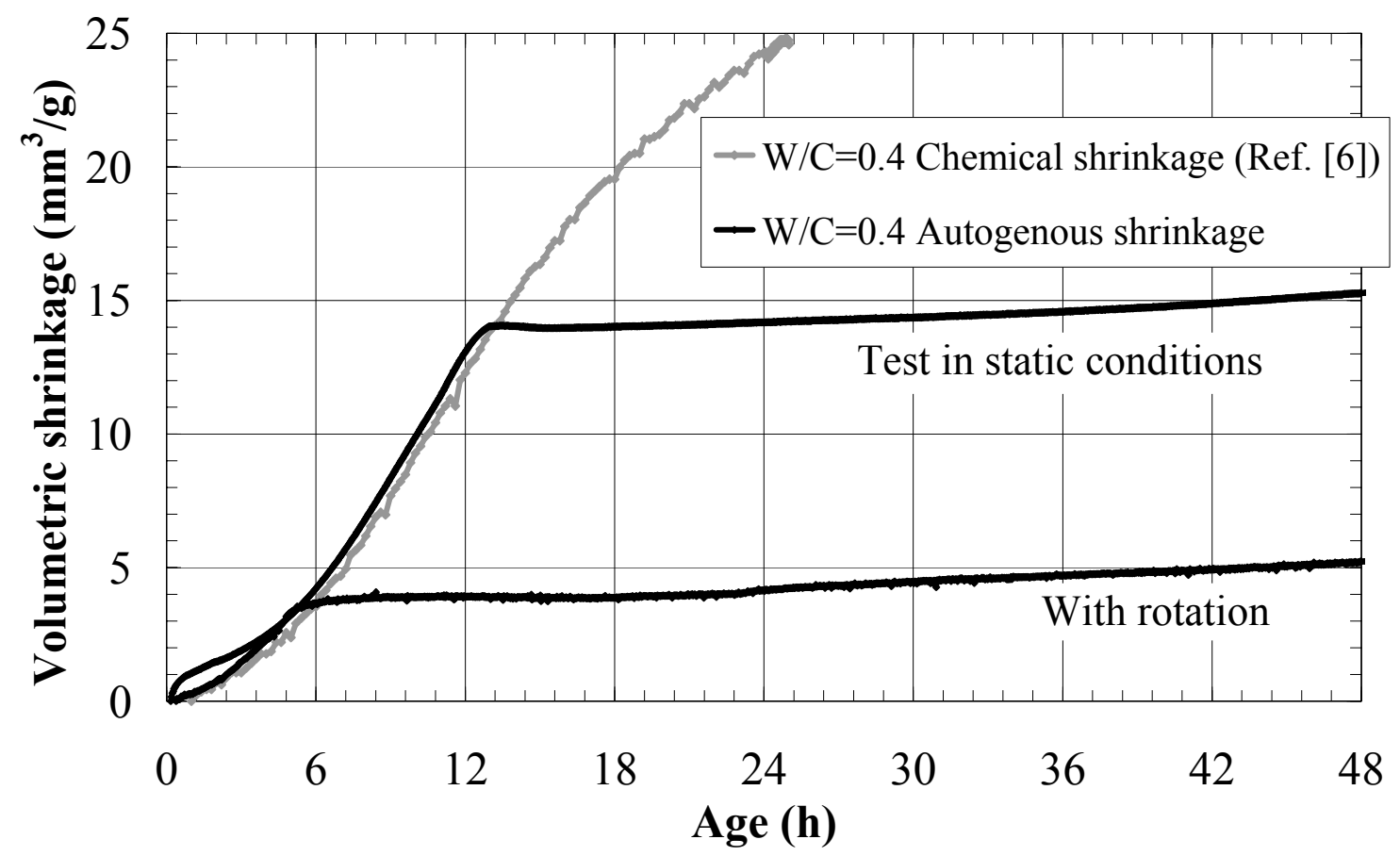

Figure 9: Comparison between chemical shrinkage and volumetric autogenous shrinkage measured with and without rotation of the sample

(Cement paste with $\mathrm{W} / \mathrm{C}=0.4$ at $\mathrm{T}=20 \pm 1^{\circ} \mathrm{C}$ )

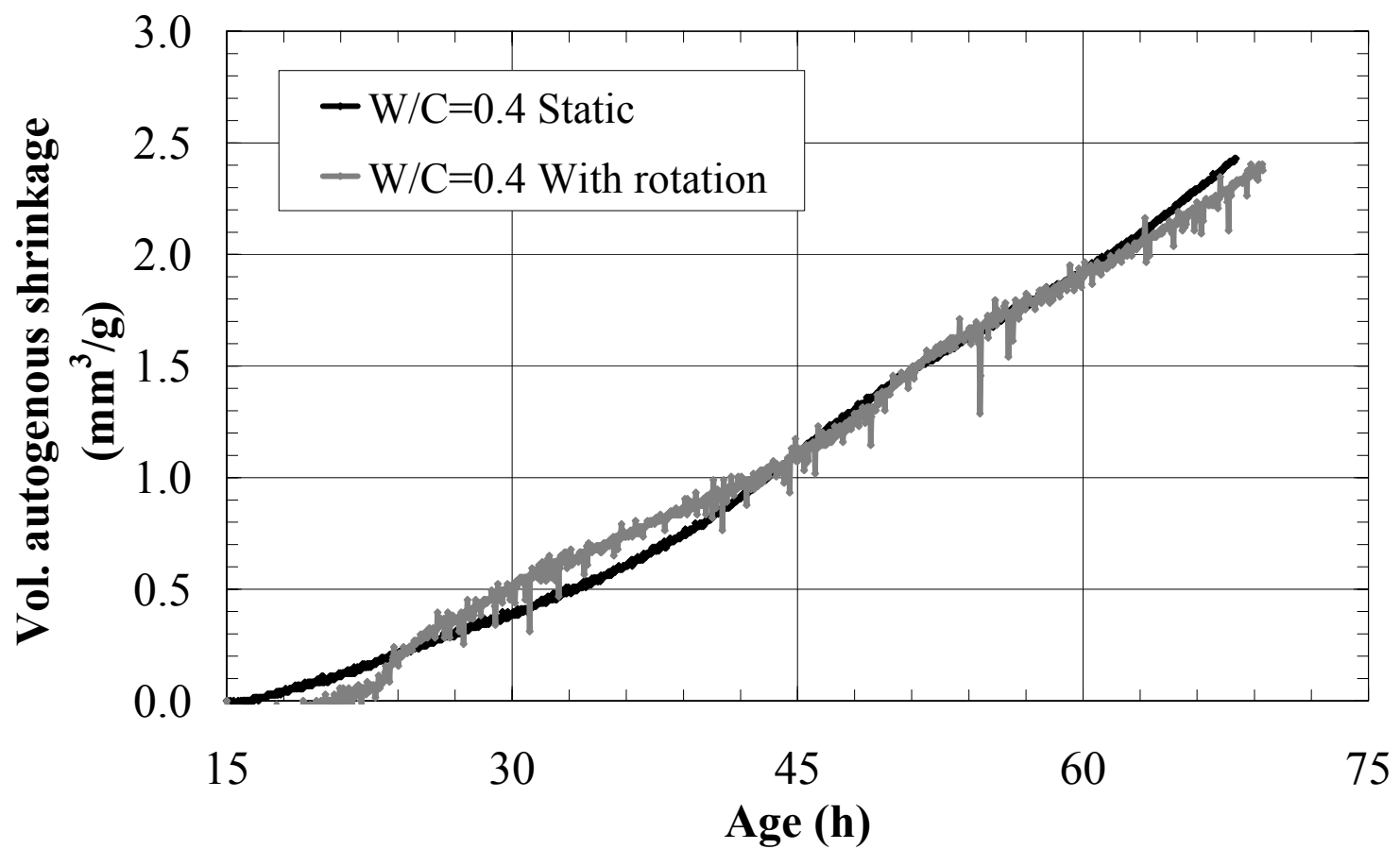

Figure 10: Volumetric autogenous shrinkage with and without rotation of the sample initialized at $15 \mathrm{~h}$ of hydration (Cement paste with $\mathrm{W} / \mathrm{C}=0.4$ at $\mathrm{T}=20 \pm 1{ }^{\circ} \mathrm{C}$ ) 


\subsection{Uniaxial autogenous deformation}

The measurement of the volume deformations (chemical or volumetric autogenous shrinkage) does not provide sufficient information to describe the material behaviour. Indeed, for concrete structure modelling, it is important to know the uniaxial deformations of the material. An improved horizontal linear autogenous shrinkage device has been developed and a second device for vertical measurement is under development.

The first results obtained with the horizontal device are presented in figures 11 and 12. One can notice in figure 11 a very good repeatability of the signal given by the two sensors located on both ends of the sample. The sensors are waterproof non-contact eddy current transducers. It is thus possible to carry out the tests in thermostatic water bath in order to maintain the sample at constant temperature. After 20 minutes of test, the sample temperature is stabilized at $20 \pm 1^{\circ} \mathrm{C}$.

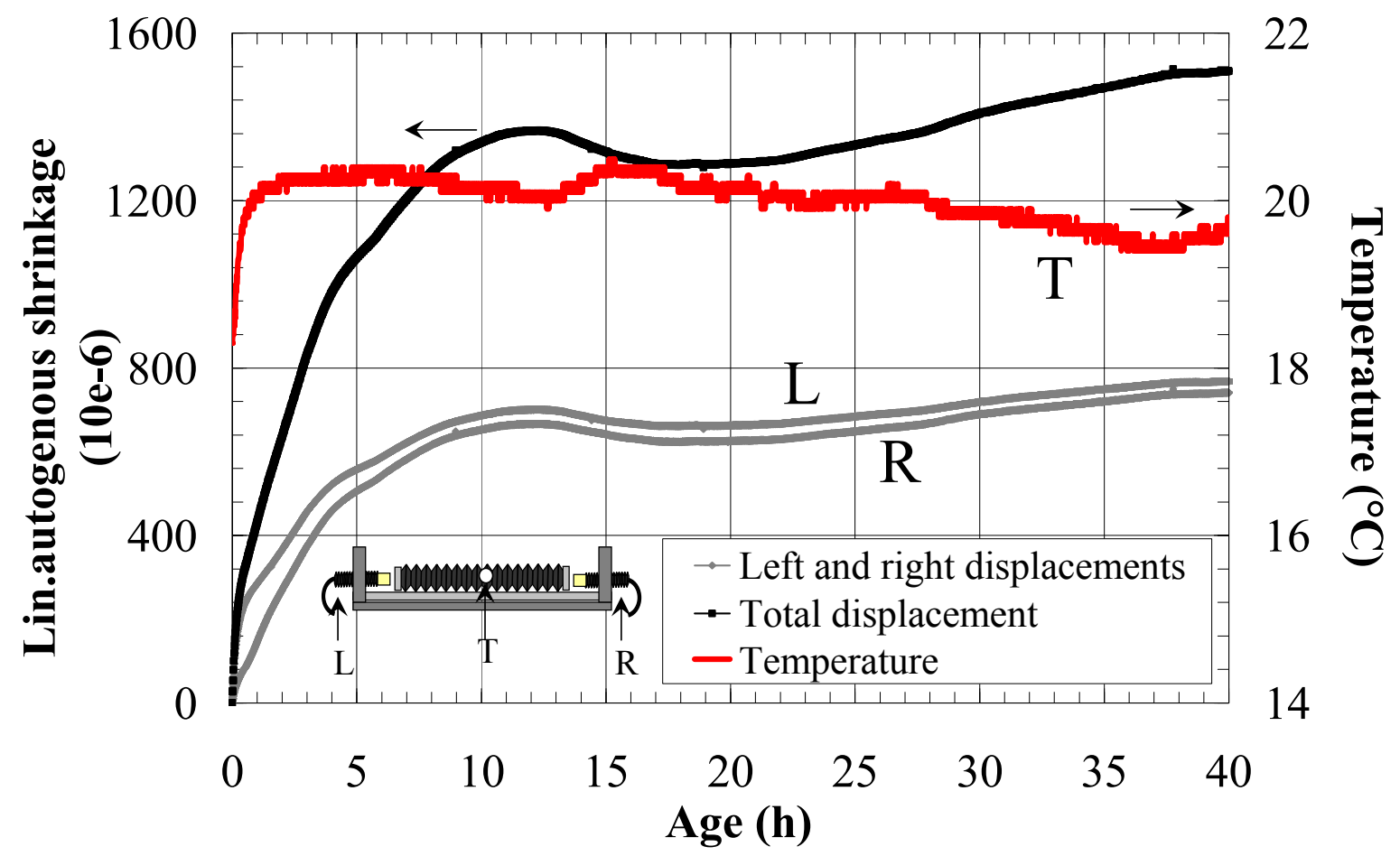

Figure 11: Horizontal linear autogenous shrinkage vs. hydration age (Cement paste with $\mathrm{W} / \mathrm{C}=0.3$ at $\mathrm{T}=20 \pm 1^{\circ} \mathrm{C}$ )

The test method is used to investigate the effect of $\mathrm{W} / \mathrm{C}$ ratio on the evolution of autogenous shrinkage. Figure 12 shows the lower the $\mathrm{W} / \mathrm{C}$ ratio the higher the autogenous shrinkage. This result is in agreement with previous studies on the subject [1]: in a cement paste with low water content, the self-desiccation is faster and more intense and thus causes a more important shrinkage. The periodic disturbances observed on figure 12 for the $\mathrm{W} / \mathrm{C}=0.25$-curve have been identified as thermal variations of the bath water between 36 and 
$70 \mathrm{~h}$. Those variations that can reach $2^{\circ} \mathrm{C}$ have been eliminated in the next tests, whose temperature history was stabilized at $20 \pm 0.1^{\circ} \mathrm{C}$.

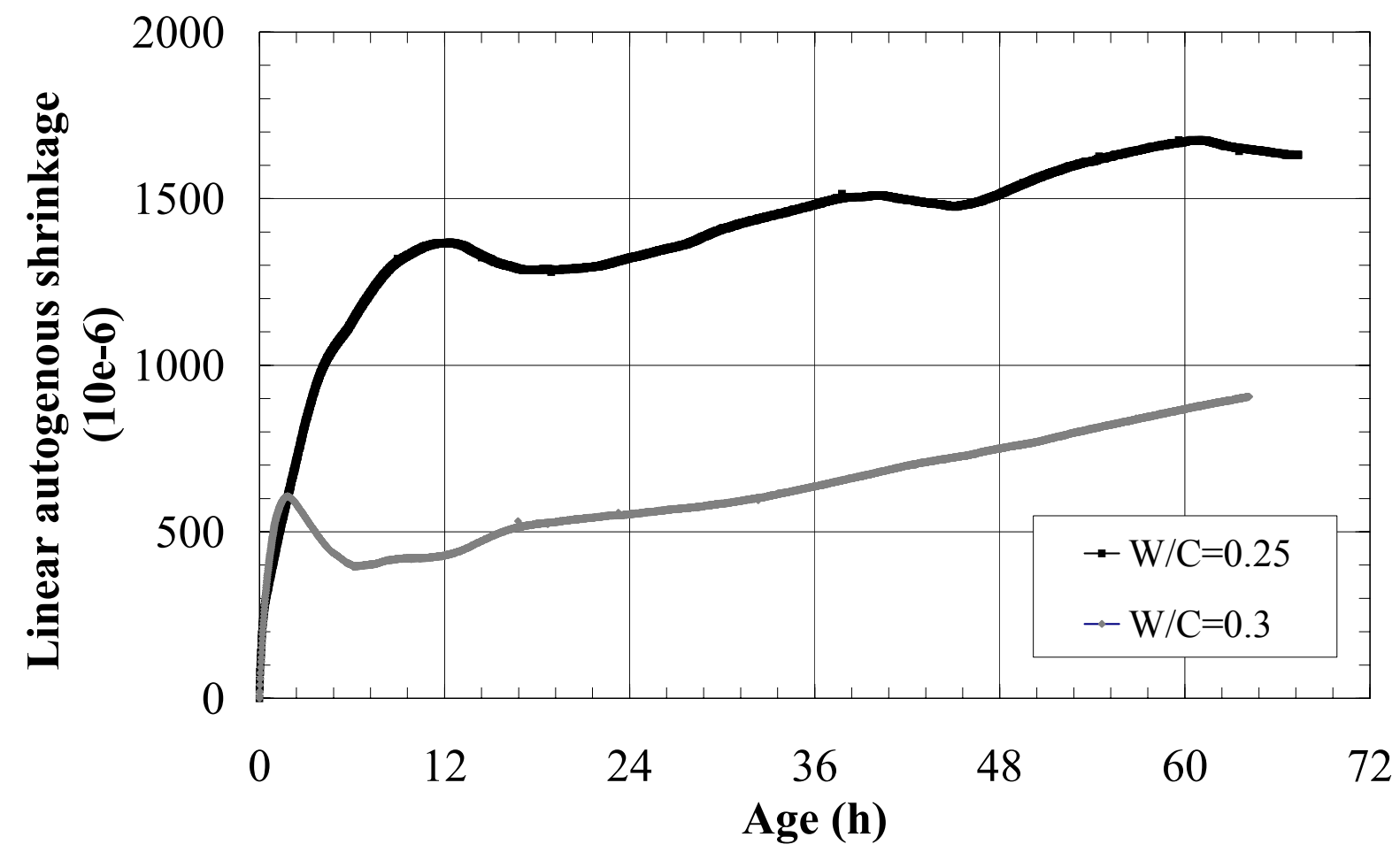

Figure 12: Effect of the $\mathrm{W} / \mathrm{C}$ ratio on the horizontal linear autogenous shrinkage (Cement pastes with $\mathrm{W} / \mathrm{C}=0.25$ and 0.3 at $\mathrm{T}=20 \pm 1^{\circ} \mathrm{C}$ )

\subsection{Isothermal ring test}

This ring test device was developed to quantify, in autogenous, quasi-isothermal and restrained conditions, the deformations of cement-based systems as well as the age of cracking, from the measuring of the steel ring deformations. Figure 13 displays the deformations of the steel ring until the cracking of the cement paste $(\mathrm{W} / \mathrm{C}=0.3)$ at $20^{\circ} \mathrm{C}$ and $25^{\circ} \mathrm{C}$. The result analysis shows that the temperature increasing causes an augmentation of the deformation rate and a shortening of the age of cracking. This phenomenon is explained by the thermoactivated characteristic of hydration reactions, which induces an acceleration of both deformations and internal stresses when the temperature increases.

In order to underline the kinetic effect of temperature, it is preferable to plot the deformations as a function of hydration degree. A continuous function of the hydration degree has been obtained using the NIST's model CEMHYD3D [11]: the value of the $\beta$-parameter, which enables to convert the number of model cycles to real time, has been fitted from experimental values measured at different temperatures and water-to-cement ratios (figure 14). In our case, the value $\beta=0.00014$ gives the best fitting. 


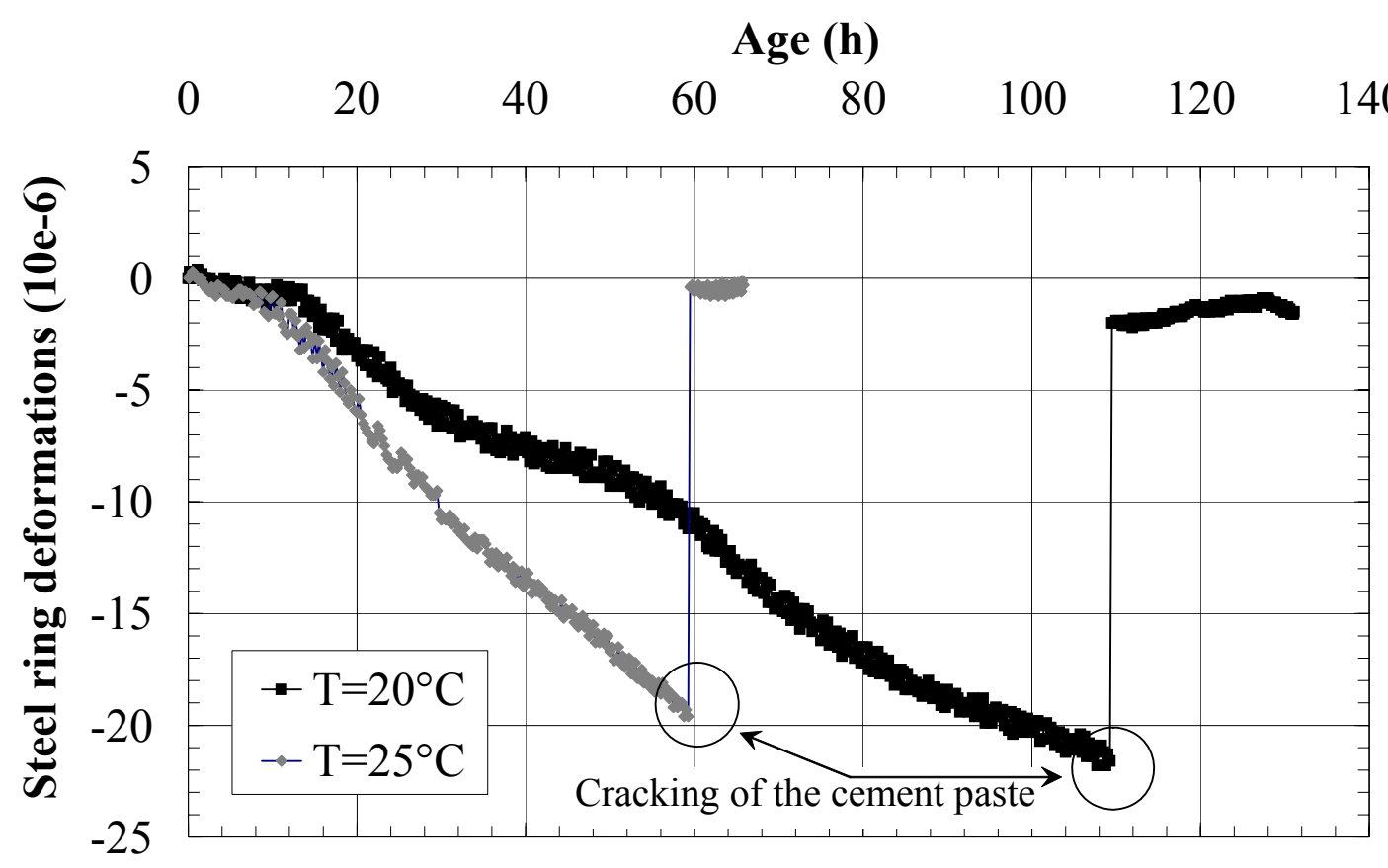

Figure 13: Steel ring deformations vs. hydration age (Cement paste with $\mathrm{W} / \mathrm{C}=0.3$ )

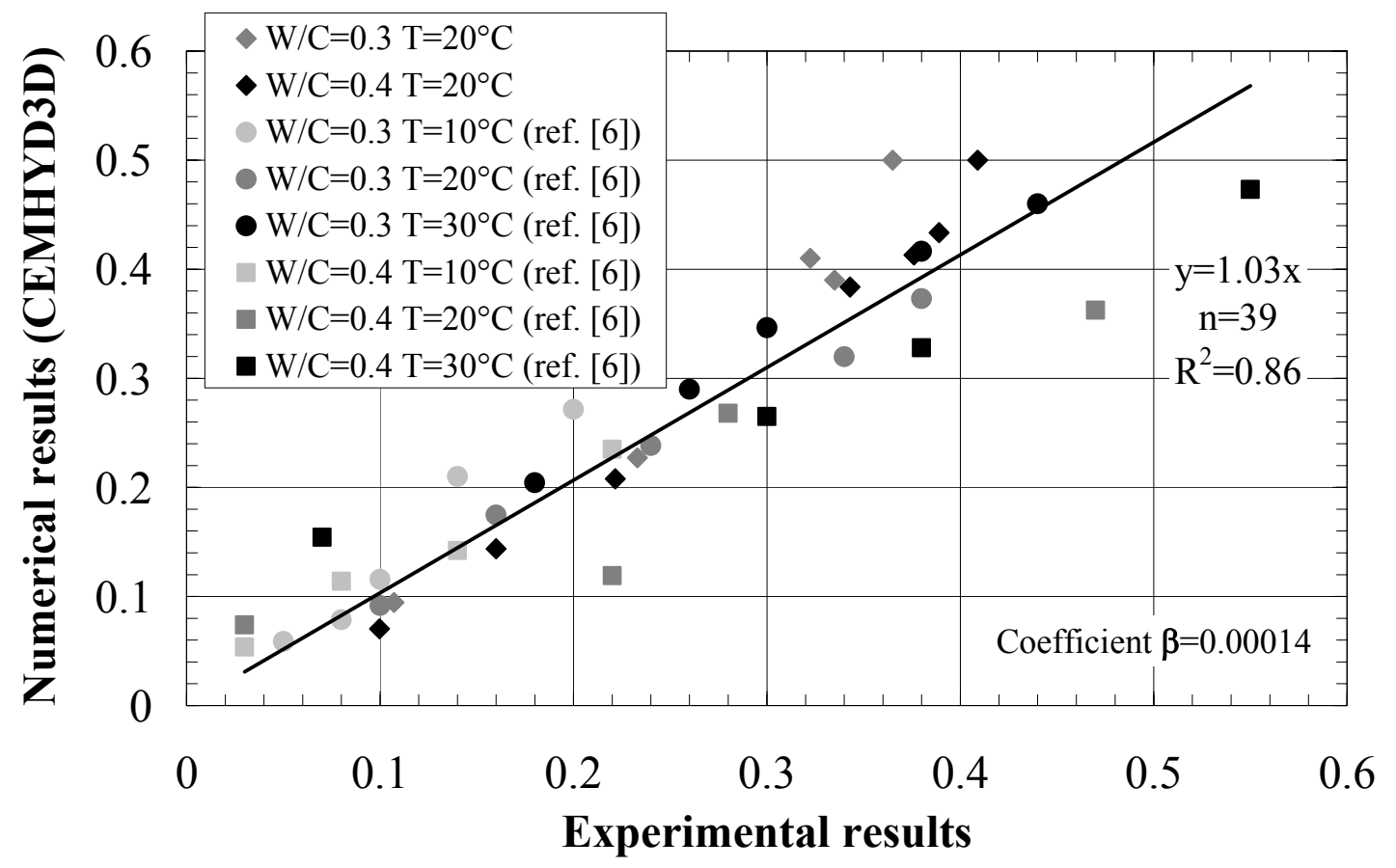

Figure 14: Comparison between numerical and experimental results of hydration degree of CEM1 cement pastes at different temperatures 
Finally, figure 15 gives the deformations of the steel ring versus the cement hydration degree progress. It shows that the two curves follow similar evolutions and that the cracking of the cement pastes at $\mathrm{T}=20^{\circ} \mathrm{C}$ and $\mathrm{T}=25^{\circ} \mathrm{C}$ appears at about the same hydration degree value equal to $0.58 \pm 0.02$.

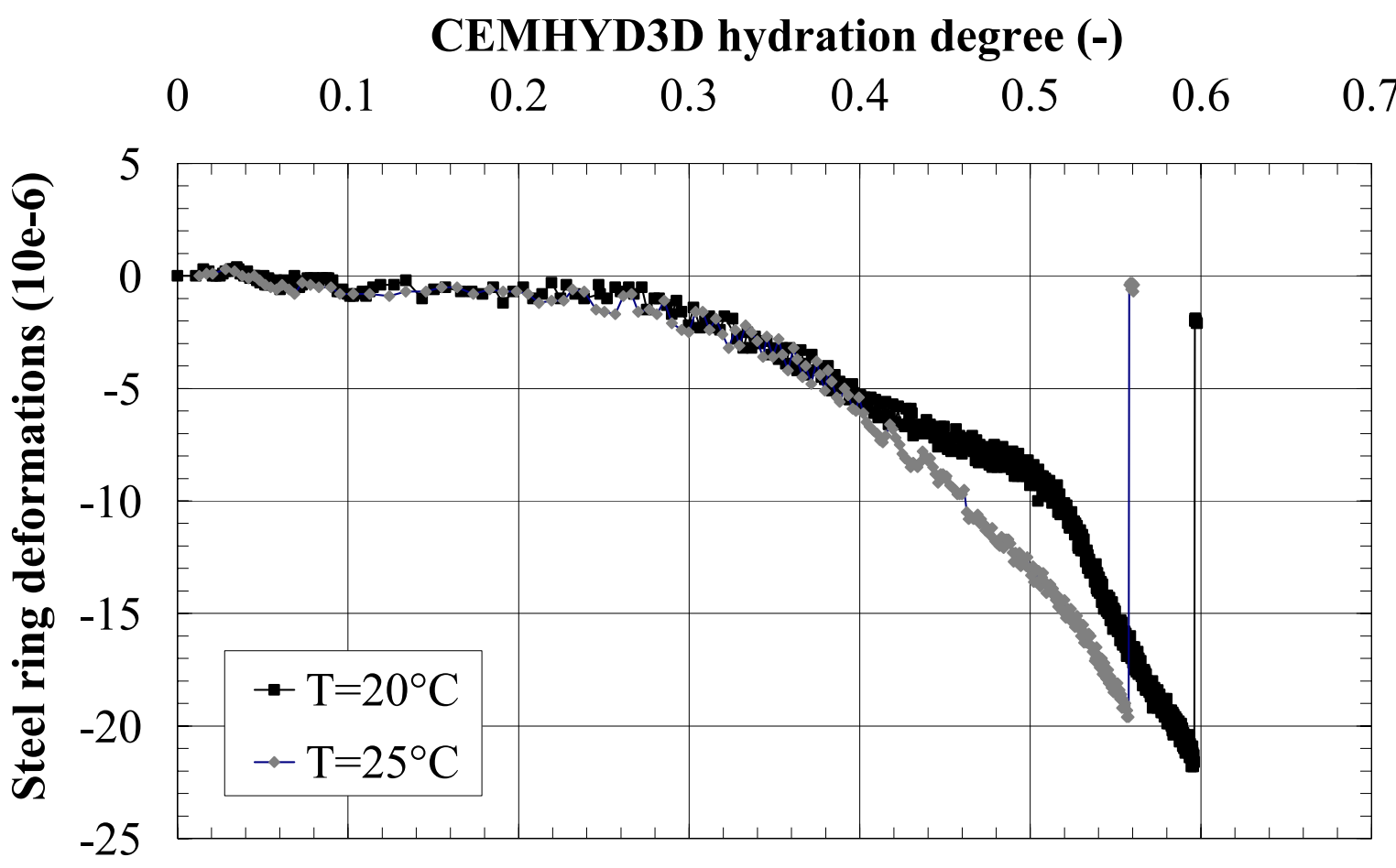

Figure 15: Steel ring deformations vs. hydration degree

(Cement paste $\mathrm{W} / \mathrm{C}=0.3$ )

\section{CONCLUSIONS}

During this study, various experimental techniques for the measurement of free and restrained deformations of cementitious matrices are described and the first results obtained are analyzed. It was in particular shown that:

- The presence of granular inclusions slightly accelerates the evolution of mortar chemical shrinkage: the crossing analysis of the results highlighted that the additional destruction of cement grain clusters during mixing can be considered as the main cause of Le Chatelier's contraction acceleration at very early age. This phenomenon does not influence significantly the quasi-linear relation between chemical shrinkage and hydration degree of the mortars.

- The bleeding phenomenon influences the measurement of cement paste volume change at very early age, by inducing an extension of the deformation phase of autogenous shrinkage dominated by Le Chatelier's contraction. This effect, which has be found significant for cement pastes with $\mathrm{W} / \mathrm{C}$ ratio $\geq 0.4$, leads to an overestimating of autogenous shrinkage. The rotary test device developed in the present study makes it possible to eliminate this artefact. 
- The use of non-contact and waterproof eddy current sensors enables to quantify precisely, in quasi-isothermal conditions and since the casting of the material, the uniaxial autogenous deformations of the cementitious systems.

- The age of cracking measured with the ring test device decreases when the temperature increases. This result can be explained by the acceleration of hydration reactions and of the development of internal stresses. However, in the temperature range investigated (20$\left.25^{\circ} \mathrm{C}\right)$, cracking appears at nearly the same cement hydration degree $(\approx 58 \pm 2 \%$ of hydration).

\section{ACKNOWLEDGEMENTS}

The authors gratefully acknowledge the support received from the Chamber of Commerce of Nantes-Saint-Nazaire and Nantes Metropole, which actively participate in funding the research work of the first author. Thanks to Ahmed Loukili and Philippe Turcry for fruitful discussion.

\section{REFERENCES}

[1] Baroghel-Bouny, V. and Kheirbek, A., 'Effect of mix-parameters on autogenous deformations of cement pastes - Microstructural interpretations', Con. Sc. Engng. 3 (9) (2001) 23-38.

[2] Justnes, H., Clemmens, F., Depuydt, P., Van Gemert, D. and Sellevold, E.J., 'Correlating the deviation point between external and total chemical shrinkage with the setting time and other characteristics of hydrating cement paste' in 'Shrinkage 2000', Proceedings of the International Conference RILEM on Shrinkage of Concrete, Paris, October, 2000 (RILEM, Paris, 2000) 57-73.

[3] Sant, G., Lura, P. and Weiss, J., 'Measurement of volume change in cementitious materials at early ages: review of testing protocols and interpretation of results'. 85th Annual meeting of the Trasportation Research Board, Washigton D.C., January, 2006.

[4] Boivin, S., Acker, P., Rigaud, S. and Clavaud, B., 'Experimental assessment of chemical shrinkage of hydrating cement paste', in 'Autoshrink'98', Proceedings of the International Workshop on Autogenous shrinkage of concrete, London, June, 1998 (E\&FN Spon, London, 1998) 81-92.

[5] Holt, E., 'Early age autogenous shrinkage of concrete', $\mathrm{PhD}$ thesis (Technical research centre of Finland, 2001).

[6] Mounanga, P., Khelidj, A., Loukili, A. and Baroghel-Bouny, V., 'Predicting $\mathrm{Ca}(\mathrm{OH})_{2}$ content and chemical shrinkage of hydrating cement pastes using analytical approach', Cem. Con. Res. 34 (2) (2004) 255-265.

[7] Justnes, H., Van Gemert, A., Verboven, F., Sellevold, E.J., 'Total and external chemical shrinkage of low W/C ratio cement pastes', Adv. Cem. Res. 8 (31) (1996) 121-126.

[8] Barcelo, L., Boivin, S., Acker, P., Rigaud, S. Boulay, C. and Clavaud, B., 'Linear vs. volumetric autogenous shrinkage measurement: material behaviour or experimental artefact?', in 'Selfdesiccation and its importance in concrete technology', Proceedings of the $2^{\text {nd }}$ International Research Seminar, Lund, June, 1999 (Lund Institute of Technology, Lund, 1999) 109-125.

[9] Hossain, A.B. and Weiss, J., 'The role of specimen geometry and boundary conditions on stress development and cracking in the restrained ring test', Cem. Con. Res. 36 (1) (2006) 189-199.

[10] Mounanga, P., 'Experimental study on the behaviour of cement pastes at very early age: hydration, shrinkage and thermal properties', PhD thesis (in French) (University of Nantes, France, 2003).

[11]Bentz, D.P., 'CEMHYD3D: A three-dimensional cement hydration and microstructure development modelling package', Report, Version 2.0, NISTIR 6485, U.S. Department of Commerce, April, 2000. 